\title{
Abuso sexual, CRianças e AdOLescentes: REFLEXÕES PARA O PSICÓlOGO QUE TRABALHA NO CREAS
}

Bruno Ricardo Bérgamo Florentino ${ }^{\star}$

Universidade Federal de São João del-Rei, São João del-Rei, MG, Brasil

\begin{abstract}
RESUMO
O abuso sexual infanto-juvenil se configura como um problema mundial, histórico e marcado por inúmeras determinações, embora seu efetivo enfrentamento tornou-se preocupação das políticas públicas somente nas últimas décadas. $O$ presente artigo, de natureza qualitativa, realizado a partir de pesquisa bibliográfica, discute as principais perspectivas do psicólogo frente esta violência, delimitando os principais aspectos que norteiam o exercício do profissional que está inserido no Centro de Referência Especializado de Assistência Social (CREAS). Os resultados apontam que se trata de uma demanda complexa, por vezes contraditória, que requer a atuação interdisciplinar, intersetorial, centrada na família, livre de tabus, preconceitos e estereótipos.
\end{abstract}

Palavras-chave: abuso sexual; crianças; adolescentes; Psicologia.

\section{SexuAl AbUSE, CHILdREN AND ADOLESCENTS: REFLECTIONS FOR A PSYCHOLOGIST WHO WORKS AT CREAS}

\begin{abstract}
The children and youth sexual abuse is configured as a global problem, and marked by numerous historical determinations, although their effective coping became a public policy concern only in last decades. This article, qualitative, conducted from literature, discusses the main perspectives of psychologists against this violence, outlining the main aspects that govern the exercise of professional who is housed at the Center for Social Assistance Specialized Reference (CREAS). The results show that it is a complex demands, often contradictory, which requires interdisciplinary, intersectoral action, family-centered, free of taboos, prejudgementes and stereotypes.
\end{abstract}

Keywords: sexual abuse; children; adolescents; Psychology.

\footnotetext{
^ Endereço para correspondência: UFSJ - Universidade Federal de São João del-Rei. Campus Dom Bosco - Praça Dom Helvécio, 74. PPGPSI - Sala 1.53. São João del-Rei /MG. CEP: 36301-160. E-mail: bruno_psicologia@hotmail.com
} 


\section{INTRODUÇÃo}

Este artigo tem como objetivo analisar o exercício profissional do psicólogo que trabalha no Serviço de Enfrentamento ao Abuso e à Exploração Sexual de Crianças e de Adolescentes do Centro de Referência Especializado de Assistência Social (CREAS), destacando as atribuições da Psicologia no contexto das políticas sociais, e, especialmente, no que se refere às políticas de atendimento e acompanhamento deste tipo de violência.

Foram destacados alguns dos principais aspectos que, segundo a literatura sobre o assunto, referem-se às principais situações que perpassam o cotidiano dos profissionais, das famílias e, sobretudo, das crianças e adolescentes vítimas de abuso sexual. Nesta direção, o estudo da produção bibliográfica sobre o tema em questão, além da participação em eventos oficiais e seminários acadêmicos relativos à política de assistência social, foram os principais procedimentos metodológicos que nortearam a construção deste artigo.

Partindo do princípio de que "[...] conhecer a realidade é condição de sua transformação" (OLIVEIRA, R.; OLIVEIRA, M., 1999, p. 19), no que se refere ao abuso sexual infanto-juvenil, no contexto das políticas públicas, torna-se fundamental que o profissional, diante de tal situação, apreenda a totalidade do processo que envolve tais casos.

Com os recentes reordenamentos institucionais no contexto das políticas públicas, sobretudo no que se refere à política de assistência social, observa-se uma constante expansão no número de Centros de Referência Especializado de Assistência Social (CREAS) - instituição responsável pelo atendimento e acompanhamento das situações que envolvem violência sexual contra crianças e adolescentes.

Neste ínterim, vale ressaltar que a política de assistência social, atualmente, é composta por diferentes categorias profissionais de nível superior, a saber: Psicologia, Serviço Social, Direito, Pedagogia, Antropologia, Filosofia, Economia Doméstica, além de outras; as quais, dependendo da constituição das equipes de referência multiprofissionais, são os profissionais responsáveis pela oferta da proteção social às vítimas de abuso sexual e seus familiares.

\section{Abuso SeXual: DelimitaÇões e deSAFios inerentes aO ATENDIMENTO E ACOMPANHAMENTO}

Furniss (1993) afirma que os profissionais que realizam o atendimento e o acompanhamento dos casos de abuso sexual contra crianças e adolescentes, inicialmente, devem ter consciência de que esta é uma questão complexa, a qual, necessariamente, precisa ser compreendida a partir de diferentes pontos de vista, dentre eles: sociológico, antropológico, político, normativo e clínico. $\mathrm{O}$ autor ressalta o quanto é difícil para os profissionais trabalharem com esta demanda, haja vista que este é um campo repleto de complexidade e conflitos tanto pessoal como profissionalmente. 
Para Minayo (2006), muitos profissionais ainda estão atuando de maneira limitada. A autora tipifica duas grandes formas ou modelos de atuação profissional que, segundo ela, tratam-se de intervenções de pouca eficiência. A primeira seria por intermédio daqueles profissionais que não saem do campo teórico e da reflexão filosófica. Já na segunda, seriam os profissionais que atuam somente na questão operacional, fundamentados e preocupados principalmente com a constatação e reparação dos danos biológicos, emocionais e sociais. A autora intensifica a necessidade de os profissionais trabalharem não apenas com modelos epidemiológicos, mas, também, com a compreensão dos contextos na abordagem dos processos violentos.

Cunha, Silva e Giovanetti (2008) também destacam a necessidade de superação deste modo de encarar a violência sexual infanto-juvenil. Para os autores, é preciso extrapolar os olhares e saberes fragmentados, uma vez que a questão é atravessada por diversas imediaticidades, exige-se que os profissionais compreendam se tratar de um fenômeno que envolve múltiplas determinações nem sempre tão aparentes ou perceptíveis, dentre as quais é possível assinalar a vulnerabilidade socioeconômica e cultural que se faz presente na maior parte do contexto das vítimas e suas famílias. Ainda que o abuso sexual ocorra em todas as classes sociais e culturas do mundo todo, os autores consideram que "[...] a realidade da violência sexual infanto-juvenil representa um fenômeno complexo que necessita ser discutido nos seus aspectos culturais, sociais, históricos e institucionais, no intuito de abranger sua complexidade" (CUNHA; SILVA; GIOVANETTI, 2008, p. 41).

Sendo os elementos histórico-culturais essenciais para a compreensão e o debate dos casos de abuso sexual praticados contra crianças e adolescentes, não é possível afirmar que as inserções socioeconômicas e culturais sejam os únicos ou mesmo os principais fatores que determinam as situações de violência, pois, ao contrário desta representação, existe uma série de outras questões igualmente relevantes que merecem a atenção (MOREIRA; VASCONCELOS, 2003).

O que ocorre, de modo geral, é que as crianças e adolescentes em situação de vulnerabilidade socioeconômica estão mais expostas a este tipo de violência e suas famílias encontram maiores dificuldades para a superação deste tipo de trauma familiar. Salienta-se que a pobreza não é a causa determinante deste tipo de situação, uma vez que outros fatores como desemprego, subemprego, baixa escolaridade, presença de álcool ou substâncias psicoativas e o histórico de violência na infância e a doença mental também representam grandes causas do abuso sexual infanto-juvenil (CUNHA; SILVA; GIOVANETTI, 2008).

Compreende-se, então, que os casos de abuso sexual são distintos entre si. Logo, as vítimas têm necessidades singulares de atendimento e acompanhamento, caracterizando, assim, um primeiro desafio posto aos profissionais que se deparam com tais situações. O Pacto São Paulo ${ }^{1}$ (MALLAK; VASCONCELOS, 2002) elenca algumas particularidades que devem ser levadas em consideração, por todos os profissionais, no momento da intervenção, sendo elas: as diferenças de estruturação e histórico familiar, as características pessoais e da personalidade dos envolvidos e a cronologia dos eventos e da natureza do abuso. Tais carac- 
terísticas, além de dificultar a padronização ou generalização das condutas de atendimento e acompanhamento, apontam para a necessidade de compreensão da singularidade de cada caso, isto é, um aspecto fundamental para o planejamento das intervenções de acordo com as necessidades dos envolvidos.

Cunha, Silva e Giovanetti (2008), na mesma direção da perspectiva anterior, propõem um modelo de proteção interativo e complexo, o qual deverá contemplar as abordagens biológica, psicológica e social como aspectos fundamentais para a realização de um trabalho interdisciplinar que efetivamente valorize as potencialidades de cada profissional, em benefício de uma intervenção mais dinâmica e eficiente no atendimento e acompanhamento das vítimas. Para tal, as circunstâncias

[...] que definem uma atenção de qualidade à saúde exigem vários olhares, reúnem diversos saberes e práticas na busca do entendimento e da construção integrada de soluções que garantam à população uma vida melhor, de acordo com o princípio da intersetorialidade ${ }^{2}$ (CUNHA; SILVA; GIOVANETTI, 2008, p. 239).

Ao serem estruturadas as condições para o atendimento e o acompanhamento dos casos de suspeita ou confirmação de abuso sexual contra crianças e adolescentes, é necessário, de antemão, definir a atribuição a ser desempenhada pelos profissionais de cada órgão ou instituição que atua direta ou indiretamente com as partes envolvidas nessa dolorosa questão, pois se trata de um drama que requer intervenções especializadas, com a confluência de diferentes categorias profissionais e a realização de ações articuladas e coordenadas (VECINA; FERRARI, 2002).

$\mathrm{O}$ êxito da intervenção realizada junto à criança ou adolescente vítima de abuso sexual, muitas vezes, depende de uma ação integrada por parte de todos os responsáveis, a destacar: as instituições e os órgãos de defesa dos direitos da criança e do adolescente; a rede de serviços de proteção social que compõem o Sistema Único de Assistência Social (SUAS); e, por fim, os profissionais que trabalham no Centro de Referência Especializado de Assistência Social (CREAS), especialmente os psicólogos, objeto de interesse deste artigo.

\section{O EXERCício PROFISSIONAL do PSICÓlogo ANTE OS CASOS DE ABUSO SEXUAL}

\section{CONTRA CRIANÇAS E ADOLESCENTES}

Para o debate da proposta em questão, abordar-se-á o exercício profissional do psicólogo que trabalha no Sistema Único de Assistência Social, mais especificamente no CREAS, o qual, no atual contexto das políticas públicas, através de sua equipe de referência (composta por psicólogos), é o responsável pela oferta do Serviço de Enfrentamento ao Abuso e à Exploração Sexual de Crianças e Adolescentes.

Sobre a inserção da Psicologia neste espaço socioocupacional, o Centro de Referência de Psicologia e Políticas Públicas ${ }^{3}$ (CREPOP, 2007, p. 26) define que: 
A prática profissional do psicólogo junto a políticas públicas de Assistência Social é a de um profissional da área social produzindo suas intervenções em serviços, programas e projetos afiançados na proteção social, a partir de um compromisso ético e político de garantia dos direitos dos cidadãos ao acesso à atenção e proteção da Assistência Social. A partir da interface entre várias áreas da Psicologia, estas ações estão sendo construídas numa perspectiva interdisciplinar, uma vez que vão constituindo várias funções e ocupações que devem priorizar a qualificação da intervenção social dos trabalhadores da Assistência Social.

Diante do exposto, o exercício profissional do psicólogo junto ao Serviço de Enfrentamento ao Abuso e à Exploração Sexual de Crianças e de Adolescentes requer, necessariamente, a articulação dos saberes psicológicos com as demais categorias profissionais, haja vista que, conforme apontado anteriormente, a ação interdisciplinar representa não só uma possibilidade viável, mas uma necessidade imperiosa ao se pensar na intervenção junto aos sujeitos - vítimas e familiares envolvidos nos casos de abuso sexual infanto-juvenil.

O Centro Regional de Atenção aos Maus Tratos na Infância, ${ }^{4}$ mais conhecido como CRAMI, sugere que, caso os sujeitos estejam sendo atendidos em outros serviços (seja da política de assistência social ou de saúde), não é aconselhável que um segundo profissional da mesma categoria trabalhe no caso, pois se considera que a vítima e sua família já se encontram inseridas em uma rede de apoio. É fundamental que toda a família tenha o direito a uma avaliação psicológica, sobretudo a criança, o adulto não agressor e, inclusive, o agressor. O objetivo de se trabalhar com toda a família é observar como cada sujeito percebe a violência ocorrida. Assim, a primeira pessoa a ser atendida deverá ser sempre a criança ou o adolescente que sofreu o abuso, de maneira que, inicialmente, a intervenção do profissional deverá se atentar para a vinculação positiva e o estabelecimento da confiança entre a equipe e os protagonistas da violência (CRAMI, 2005).

No momento do atendimento ou acompanhamento, é fundamental acolher a vítima e dar a ela o tempo necessário para refletir, elaborar e compartilhar suas experiências dolorosas. Independente do modo como a história seja narrada ao profissional (neste caso, ao psicólogo), a criança ou o adolescente precisa ser respeitada e merece ser escutada como sujeito que detêm uma realidade física e psíquica. Em outros termos, significa que a narrativa precisa receber os devidos créditos no momento em que a vítima estiver relatando como a situação abusiva ocorreu (PRADO et al., 2004).

Furniss (1993), sabiamente, esclarece que existe um movimento de intensa motivação envolvida no processo entre a escuta profissional e a narrativa das vítimas do abuso, pois o conteúdo verbalizado (ou não) pela criança ou pelo adolescente está diretamente relacionado com a capacidade receptiva que o psicólogo possui para lidar com tais casos. Isto porque a todo o momento o psicólogo envia: 
[...] mensagens muito sutis a clientes e famílias sobre aquilo que eles podem e aquilo que não podem nos contar. Eu iria ao ponto de dizer que a emergência de questões inconscientes do cliente e paciente é fortemente influenciada por nossa própria motivação, como profissionais, para trazer à luz essas questões. Precisamos conhecer e observar os limites de nossas próprias capacidades de manejar a situação, e precisamos estar conscientes de nossas necessidades de apoio pessoal, profissional [...] (FURNISS, 1993, p. 43).

Seguindo esta perspectiva de raciocínio, acolher e escutar as situações de abuso sexual relatadas por crianças, adolescentes e seus familiares, constitui-se um grande desafio ao exercício profissional do psicólogo que trabalha no CREAS, visto que, no momento da intervenção, o profissional se depara com sentimentos de raiva, fascínio, inquietação, perplexidade e outros conteúdos que poderão vir à tona durante o atendimento ou acompanhamento do caso. Prado et al. (2004) esclarece que isto pode ocorrer pelo fato de que situações que envolvem o abuso sexual infanto-juvenil, muitas vezes, desperta no profissional os próprios medos infantis, levando-os a lançar mão do uso de determinados mecanismos de defesa - como a negação, por exemplo - e até mesmo a se ver diante de uma intensa angústia, a ponto de desejar não ser ele a pessoa a ter de se responsabilizar pelo atendimento ou acompanhamento do caso.

Deste ou daquele modo, as crianças e os adolescentes precisam sentir que podem confiar e revelar o abuso sexual sem serem rejeitadas ou punidas pelos profissionais. Os psicólogos precisam estar aptos para conceder, às vítimas, uma permissão explícita para verbalizar o abuso sexual, sendo que, caso necessário, o próprio profissional deverá introduzir uma linguagem sexual para que o sujeito sinta liberdade para tratar do assunto. Para tal, é preciso estar livre de preconceitos, tabus ou qualquer tipo de obstáculo que venha a reforçar questões que há muito tempo estão embutidas em nossa cultura e sociedade, como, por exemplo, o pensamento acerca da onipotência dos pais contra os filhos (FURNISS, 1993).

Uma das principais atribuições do psicólogo do CREAS, ao iniciar o atendimento ou acompanhamento junto às vítimas, consiste em estar habilitado a identificar quais são os danos emocionais (já instalados) e a gravidade dos mesmos (CRAMI, 2005). As ações devem ser planejadas de modo a permitir uma intervenção especializada, personalizada e individual, onde os profissionais possam alcançar as determinações subjetivas que reforçam sua reprodução no tempo e no espaço (CUNHA; SILVA; GIOVANETTI, 2008).

O Pacto São Paulo (MALLAK; VASCONCELOS, 2002) destaca que a psicoterapia individual é uma estratégia indispensável no momento de se intervir junto às crianças e adolescentes vítimas de abuso sexual, pois, ao mesmo tempo em que trabalha a confusão proveniente da situação abusiva, organiza o material inconsciente e as emoções "encapsuladas". Ademais, a psicoterapia individual 
também auxilia a criança ou o adolescente a reconhecer seus próprios sentimentos (raiva, dor, mágoa, revolta, etc.) e a discriminar um do outro, desfazendo, em partes, a desordem causada pelo abuso sexual.

Um elemento extremamente necessário de se trabalhar junto à vítima que sofreu abuso sexual é a culpa, ajudando-a a compreender a responsabilidade do abusador e a diminuir seus sentimentos de vergonha e autoacusação. Para isto, a psicoterapia individual possibilita a elaboração das consequências traumáticas, diminui a intensidade da ansiedade e das emoções relativas ao trauma. Isso só é possível, em alguns casos, à medida que o psicólogo trabalha com as várias representações da experiência traumática (sensações, emoções, imagem corporal e ações) (MALLAK; VASCONCELOS, 2002).

Todavia, as atribuições do psicólogo frente aos casos de abuso sexual infanto-juvenil são bem mais amplas do que meramente ajudar a criança ou o adolescente a reparar, esquecer ou superar a situação traumática e as consequências decorrentes da situação violenta. No entanto, Saraceno (1999) aponta que, infelizmente, diversos profissionais ainda realizam intervenções pontuais e descontextualizadas, tão somente para atender as situações específicas de crise ou danos decorrentes do abuso sexual. Isso ocorre em decorrência do modelo hegemônico de atendimento e acompanhamento dos casos, os quais, ainda hoje, é centrado no paradigma médico que, apesar de acolher algumas proposições das abordagens psicossociais, se caracteriza por ser um modelo linear, ${ }^{5}$ individualista $^{6}$ e a-histórico.

Por mais capacitado e habilitado que o psicólogo esteja - do ponto de vista teórico- metodológico -, uma "[...] terapia altamente qualificada pode ser muito antiterapêutica e psicologicamente prejudicial, quando é conduzida sem considerar o contexto mais amplo" (FURNISS, 1993, p. 94). Em outros termos, dizer que é fundamental considerar "o contexto mais amplo" implica trazer para o debate outros aspectos que atravessam a realidade da criança ou do adolescente acometidos pelo abuso sexual, a saber: a organização da família; as formas de relacionamento entre os membros familiares; a inserção da família no contexto comunitário e social; e, inclusive, a estrutura da sociedade como um todo.

As diretrizes da Política Nacional de Assistência Social (PNAS) acerca do trabalho social realizado pelos profissionais de nível superior, norteiam-se para o fortalecimento da função protetiva da família. Isto significa que, antes de realizar qualquer tipo de intervenção junto às vítimas e/ou seus familiares, os psicólogos devem ter a compreensão de que o público do CREAS encontra-se em posição de extrema vulnerabilidade social, caso contrário, não dependeriam deste equipamento público para organizar situações pessoais.

Por essa razão, este serviço deve desenvolver um conjunto de procedimentos técnicos especializados para atendimento e proteção imediata às crianças e aos adolescentes abusados ou explorados sexualmente, assim como seus familiares, proporcionando-lhes condições para o fortalecimento da sua autoestima e o restabelecimento de seu direito à convivência familiar e comunitária (BRASIL, 2006, p. 10-11). 
Pressupondo que a família representa uma instituição social básica, ou melhor, fundamental para a sobrevivência dos indivíduos justamente por carregar a expectativa de proteger seus membros, transmitir a cultura, as regras sociais e as relações de solidariedade, além da função mantenedora de diversas necessidades do homem, a família possui um papel central no amortecimento de eventos sociais negativos e particulares. Independentemente do tipo de família em questão (patriarcal, matriarcal, tradicional, não-tradicional, etc.) e dos fenômenos sociais que atualmente interferem em nossa sociedade, o grupo familiar ainda possui a importante tarefa de dar suporte aos seus membros (ROMARO; CAPITÃO, 2007).

Existindo a convergência das categorias abuso sexual e família, é possível distinguir o debate a partir de duas situações relevantes ao psicólogo que trabalha no CREAS: os casos em que o abusador é membro da família, caracterizando, assim, algum tipo de vínculo familiar ou relação de confiança (abuso sexual intrafamiliar); os casos em que a vítima e o agressor não possuem nenhum tipo de vínculo, caracterizando o abuso sexual extrafamiliar.

Nas famílias em que ocorreu o abuso sexual intrafamiliar, certamente, o agressor estará submetido a um processo judicial de responsabilização pelo seu ato. No entanto, isso não impede que o mesmo receba auxílio terapêutico. A literatura aponta que é importante pensar um trabalho junto a esse agressor. Furniss (1993, p. 155) afirma que, caso os profissionais realmente queiram romper com o ciclo de abusar e sofrer abuso sexual, é preciso "[...] criar um contexto no qual as pessoas que abusam sejam capazes de revelar e buscar ajuda terapêutica".

Vale ressaltar que, por maiores que sejam as dificuldades, o profissional que se dispuser ao atendimento e acompanhamento do agressor, jamais poderá assumir uma postura acusatória. Além de tal atitude ser eticamente incorreta, em nada ajudará a proteger a vítima e melhorar a situação da família como um todo. Deste modo, ratifica-se a afirmação de que o psicólogo deve se atentar para a não contaminação por emoções pessoais diante de uma possível intervenção junto ao agressor.

Por fim, considera-se fundamental que o trabalho do psicólogo junto ao Serviço de Enfrentamento ao Abuso e à Exploração Sexual de Crianças e de Adolescentes oferecido no CREAS, esteja alinhado com as demais políticas setoriais. A estruturação das ações, dos serviços, programas e projetos, a princípio, devem estar em conformidade com o Estatuto da Criança e do Adolescente (ECA), com a Lei Orgânica de Assistência Social (LOAS), com a Política Nacional de Assistência Social (PNAS), com a Norma Operacional Básica do Sistema Único de Assistência Social (NOB-SUAS) (BRASIL, 1990, 1993, 2005) e todas as demais legislações pertinentes ao exercício profissional do psicólogo que trabalha no CREAS. 


\section{CONSIDERAÇÕES FINAIS}

Diante da discussão apresentada, até o momento, percebe-se que o trabalho do psicólogo frente aos casos de abuso sexual praticado contra crianças e adolescentes é um desafio complexo, por vezes, contraditório aos próprios profissionais que se deparam diante de atrocidades, as quais lhes exigem diversas habilidades até mesmo pessoais.

As diretrizes do trabalho social, postas pelos diversos autores e instituições preocupadas com a temática em questão, evidenciam a prioridade de se trabalhar numa perspectiva de fortalecimento da família e seus vínculos. Isto significa que os psicólogos devem realizar intervenções no sentido de minimizar os impactos negativos e as consequências do abuso sexual. No entanto, as possibilidades de intervenção não se esgotam nesta perspectiva. Para além de minimizar os danos ocasionados pelo abuso sexual, o psicólogo deve pensar estratégias para que a família tenha condições de resgatar a convivência familiar, obviamente, deste que a situação de violência tenha cessado.

A centralidade na família, tida como uma estratégia fundamental para se trabalhar com os casos de abuso sexual infanto-juvenil, por sua vez, não se trata de uma preocupação única e exclusiva do psicólogo que se depara com tais situações. O Estado e a sociedade, de modo geral, também possuem sua parcela de responsabilidade, logo, também deverão ampliar suas possibilidades de desempenhar as funções de socializar e proteger seus membros.

Neste contexto, o trabalho interdisciplinar e intersetorial se torna um forte aliado, visto que as situações de abuso sexual desorganizam não só os processos psíquicos, mas toda a dinâmica familiar. Mesmo nas situações em que ocorre o abuso sexual intrafamiliar, o contexto deve ser analisado com certa cautela, afinal, em muitos casos, observa-se que o agressor e toda a família também possuem diversos direitos violados e são privados de determinadas possibilidades para desenvolver-se.

A partir da perspectiva apresentada anteriormente, o psicólogo deve estar habilitado para realizar sua intervenção livre de preconceitos, tabus ou qualquer outro obstáculo que venha reforçar questões já embutidas em nossa sociedade, como, por exemplo, a onipotência dos pais para com os filhos, ou mesmo negar a sexualidade das crianças e dos adolescentes.

Considerando a diversidade de fatores que antecedem as situações de abuso sexual, é interessante que as estratégias desenvolvidas pelos psicólogos busquem alterar a dinâmica familiar em sua totalidade, possibilitando, a partir do atendimento e acompanhamento realizado no âmbito do CREAS, a emergência de novas formas de relacionamentos.

No entanto, a intervenção do psicólogo junto à vítima (e sua família) irá depender, obviamente, da natureza, da gravidade da violação, dos arranjos internos e das vulnerabilidades instaladas no contexto familiar e comunitário. É sabido que o enfrentamento deste tipo de violência encontra grandes e diferentes 
obstáculos, a destacar: o silêncio das famílias; a inoperância de algumas instituições em que os profissionais estão inseridos; além da ausência de políticas públicas efetivas para garantir proteção social às nossas crianças e adolescentes.

A complexidade e multicausalidade das situações de abuso sexual tornam inviável um modelo padronizado de intervenção profissional. Cada situação demanda estratégias, atividades, encaminhamentos e tempos diferenciados de atendimento e acompanhamento. Não se rompe com situações violentas sem mudanças na maneira de ser diante do mundo. A nossa própria mudança se entrelaça à mudança do próximo. O desafio está lançado para todos nós - cidadãos, profissionais, crianças, adolescentes e adultos. Cada um possui a sua parcela de responsabilidade e a sociedade humana (como um todo) deve se responsabilizar pelas crianças e adolescentes. É fundamental termos conhecimento do problema, do seu tamanho e sua extensão. Urge a necessidade de uma tomada de posição coletiva frente à vida de nossas crianças e adolescentes, cidadãos como nós, amanhã jovens, futuros adultos brasileiros.

\section{Notas}

${ }^{1}$ Em setembro de 2000, foi criado o "PACTO SÃO PAULO CONTRA VIOLÊNCIA, ABUSO E EXPLORAÇÃO SEXUAL DE CRIANÇAS E ADOLESCENTES”, coordenado por 3 organizações: CRAMI-ABCD, CONDECA (Conselho Estadual dos Direitos da Criança e do Adolescente) e VISÃO MUNDIAL (ONG presente em 96 países). O Pacto São Paulo surgiu da necessidade de articular parceiros para a construção de um trabalho em rede a fim de combater o atual quadro de exploração sexual de crianças e adolescentes.

${ }^{2}$ Intersetorialidade é a articulação entre sujeitos de setores sociais diversos e, portanto, de saberes, poderes e vontades diferentes para enfrentar problemas complexos. É uma nova forma de trabalhar, de governar e de construir políticas públicas que pretende a superação da fragmentação dos conhecimentos e das estruturas sociais para produzir efeitos mais significativos na saúde da população.

O Centro de Referência Técnica em Psicologia e Políticas Públicas - CREPOP surgiu para oferecer à Psicologia um novo olhar sobre os compromissos com as Políticas Públicas e com os Direitos Humanos. O CREPOP traz, como principal propósito, ampliar a atuação dos psicólogos e das psicólogas na esfera pública, expandindo a contribuição profissional da Psicologia para a sociedade brasileira e, consequentemente, colaborando para a promoção dos Direitos Humanos no país.

${ }^{4}$ O CRAMI - Centro Regional de Atenção aos Maus Tratos na Infância do ABCD - é uma Organização Não Governamental fundada em 1988 e declarada de Utilidade Pública Municipal, Estadual e Federal que presta atendimento psicossocial a crianças e adolescentes vítimas de violência doméstica, violência sexual e abuso sexual, desenvolvendo ações preventivas que lhes possibilite defesa e proteção.

5 Linear no sentido de que é danificado alguma parte do sistema do nosso corpo, provocando uma condição de doença, onde os tratamentos são reparações dirigidos somente a este dano.

${ }^{6}$ Individualista porque saúde e doença são condições determinadas pelos recursos ou carências do indivíduo e somente dele, descaracterizando os aspectos estruturais da sociedade.

A-histórico porque o profissional ignora as interações indivíduo-ambiente. 


\section{REFERÊNCIAS}

BRASIL. Ministério da Justiça. Lei $n^{\circ}$ 8.069, de 13 de julho de 1990. 1990. Dispõe sobre o Estatuto da Criança e do Adolescente e dá outras providências. Disponível em: <http://www.planalto.gov.br/ccivil_03/leis/18069.htm>. Acesso em: 12 jan. 2012.

BRASIL. Ministério da Previdência e Assistência Social. Lei $n^{\circ}$ 8.742, de 7 de dezembro de 1993. 1993. Lei Orgânica da Assistência Social. Dispõe sobre a organização da Assistência Social e dá outras providências. Disponível em: $<$ http://www.planalto.gov.br/ccivil_03/leis/L8742.htm>. Acesso em: 15 jan. 2012.

BRASIL. Ministério do Desenvolvimento Social e Combate à Fome. Política Nacional de Assistência Social. Brasília: MDS, 2005.

BRASIL. Ministério do Desenvolvimento Social. Centro de Referência Especializado de Assistência Social - CREAS. Guia de Orientação do CREAS n. 1, 1 versão. Brasília: SNAS, 2006.

CENTRO REGIONAL AOS MAUS-TRATOS NA INFÂNCIA. Abuso sexual doméstico: atendimento às vítimas e responsabilização do agressor. 2. ed. Brasília: Unicef, 2005.

CENTRO DE REFERÊNCIA TÉCNICA EM PSICOLOGIA E POLÍTICAS PÚBLICAS. Referências técnicas para atuação do/a psicólogo/a no CRAS/ SUAS. Brasília: CFP, 2007.

CUNHA, E. P.; SILVA, E. M.; GIOVANETTI, A. C. Enfrentamento à violência sexual infanto-juvenil: expansão do PAIR em Minas Gerais. Belo Horizonte: UFMG, 2008.

FURNISS, T. Abuso sexual da criança: uma abordagem multidisciplinar. Porto Alegre, RS: Artes Médicas, 1993.

MALLAK, L. S.; VASCONCELOS, M. G. O. M. (Org.). Compreendendo a violência sexual em uma perspectiva multidisciplinar. Carapicuíba, SP: Fundação Orsa Criança e Vida, 2002.

MINAYO, M. C. de S. Violência e Saúde. Rio de Janeiro: Fiocruz, 2006.

MOREIRA, E. M.; VASCONCELOS, K. E. L. Infância, infâncias: o ser criança em espaço socialmente distintos. Serviço Social e Sociedade, João Pessoa, v. 76, p. 165-174, 2003. 
OLIVEIRA, R. D. de; OLIVEIRA, M. D. de. Pesquisa social e ação educativa: conhecer a realidade para poder transformá-la. In: BRANDÃO, C. R. (Org.). Pesquisa participante. São Paulo: Brasiliense, 1999. p. 17-33.

PRADO, M. C. C. A. et al. O mosaico da violência. São Paulo: Vetor, 2004.

ROMARO, R. A; CAPITÃO, C. G. As faces da violência: aproximações, pesquisas, reflexões. São Paulo: Vetor, 2007.

SARACENO, B. Libertando identidades: da reabilitação psicossocial à cidadania possível. Belo Horizonte: Te Corá, 1999.

VECINA, T. C. C; FERRARI, D. C. A. O fim do silêncio na Violência familiar. 2. ed. São Paulo: Ágora, 2002.

Recebido em: 21 de abril de 2012 Aceito em: 26 de fevereiro de 2014 